http://jmscr.igmpublication.org/home/ ISSN (e)-2347-176x ISSN (p) 2455-0450

crossref DOI: https://dx.doi.org/10.18535/jmscr/v8i4.49

\title{
Role of Negative Pressure Wound Therapy in the Management of Diabetic Foot Ulcers
}

\author{
Authors \\ Dr Krishna Girish A*, Dr Prabhakara GN, Dr Sharath Kumar S \\ Sri Siddhartha Medical College Hospital \& Research Centre, Agalakote, Tumkur, karnataka. \\ *Corresponding Author \\ Dr Krishna Girish A \\ Junior Resident, Department Of General Surgery, SSMC, Tumkur, India
}

\begin{abstract}
Purpose: To compare the efficacy of negative pressure wound therapy with conventional dressing in the treatment of diabetic foot ulcers.

Materials and Methods: The study included 48 patients randomized into two groups (24 patient for negative pressure wound therapy and 24 patient for conventional wound dressing) suffering from diabetic foot wounds.

Results: Patients subjected to NEGATIVE PRESSURE WOUND THERAPY were classified as Study groupand those who underwent conventional povidine iodine wound dressings were classified as control group.The age of the patients varied from 35 to 75 years. Maximum number of cases belong to the age group of 35 to 45 years. In both study and control group diabetes is more common among males compared to females. Among them $79.2 \%$ of the patients were male and $20.8 \%$ were female. The patients in both groups were subjected to split thickness skin grafting as the final treatment modality. The graft up-take was then assessed at the end of the 5th post-operative day as the percentage of ulcer surface area.In study group $93 \%$ graft take up was seen while it was 84\% in the control group.Duration of hospital stay as number of days of admission in the hospital is as above.The mean duration of hospital stay in Study group was 40.3 and 18.1 in the control group.

Conclusion: In the present study it was concluded that negative pressure wound therapy by forming healthy granulation tissue helps in better graft take up than theconventional dressing. Because of enhanced healing and overall hospital stay, the postoperative complications were less in negative pressure wound therapy. Negative pressure wound therapy dressing can be considered as superior option in management of diabetic ulcers. An easy and cheap alternative method of NPWT to the extremity wounds using sterile surgical gloves. NPWT turned out to be a good alternative with respect to the duration and cost of treatment and ergonomically better in the management of extremity wounds. NPWT dressing thus is an effective and widely available therapeutic agent in wound healing.

Keywords: Conventional Dressing, Negative Pressure Wound Therapy, Skin Grafting.
\end{abstract}

\section{Introduction}

Wound and their management are fundamental to the practice of surgery. Dressings are applications for wounds, burns, ulcers and other skin lesions to provide the ideal environment for wound healing ${ }^{[1]}$. Physiological wound healing requires a 
complex series of over lapping phases: hemostasis, inflammation, proliferation and remodeling $^{[2]}$.

It is estimated that in 2005 around 150 million people worldwide, who were affected by diabetes mellitus lived in developing countrie ${ }^{[3]}$. The lifetime risk for foot ulcers in people with diabetes has been estimated to be $15 \%$.

The application of NPWT to a wound provides a moist wound healing environment, early appearance of granulation tissue which is the standard of care for wound healing ${ }^{[4]}$. Hence, this study intends to establish healing rate is more rapid in $\mathrm{NPWT}^{[5]}$.

\section{Materials and Method}

A prospective study included 48 patients with diabetic ulcers admitted in Sri Siddhartha Medical College presenting with diabetic foot ulcer who are undergoing negative pressure wound therapy will be enrolled for the study after obtaining the written informed consent. satisfying all the inclusion criteria mentioned below after obtaining the clearance from the ethical committee.

\section{Inclusion Criteria}

- Grade-I, II, III, IV Meggit-Wagner clinical classification of diabetic foot Ulcers.

- Patients with controlled Diabetes mellitus with OHA or insulin.

\section{Methods of Collection of Data}

The selected patients are subjected to,

- A Proforma will be used to collect all the data from the patients with written informed consent between two groups. The sample size is 48 patients. Of these 24 patients received NPWT dressings were classified as Study group and 24 were treated with Conventional povidine iodine wound dressings were classified as control group.

- All cases will be followed up to discharge and subsequently for a follow up on 1st week.
- The surface area of the wound was measured, tracing the outline on transparent paper. This outline was transferred to graph paper and size was measured and recorded in both the groups.

\section{Method}

After debridement, The surrounding area of the wound is covered with paraffin gauze. The suction tube is made of the Ryles tube on to which multiple holes are made. A sterilized sponge of 4 $\mathrm{cm}$ in thickness is tailored according to the size of the wound. A longitudinal slit is made through half the thickness of the sponge which the suction tube is inserted. This is placed over the paraffin gauze, and a sterile glove of no. 8 size is stretched over it. The suction tube is taken out through the edge of the glove. Tincture benzoin is taken onto gauze and wiped over the surrounding area and the edge of the wound. Once tincture got dried, an air seal is made. A piece of transparent adhesive tape folded on itself with adhesive surface outside is plastered over the adjoining skin, over which the suction tube is placed and then a large piece of transparent adhesive tape is used to cover the whole edge of the gloves and skin. The tube is then connected to the suction machine to check for any leaks. Intermittent vacuum at -80 to -125 $\mathrm{mmHg}$ for $30 \mathrm{~min}$ is applied to the tube every 2 hours in the ward for 3 days. A 12- to 24-h gap between changing the vacuum dressings has been observed to decrease maceration. The NPWT application was continued until a desired level of granulation tissue was formed.

We used this method for the management of extremity raw area in 48 patients between 24 months (November 2017 to November 2019) at the Department of General Surgery, The indication was and diabetic foot wound. The age group ranged from 35 to 75 years. There were 10 females and 38 males. It was used for lower extremity wounds.

Dressings were done on a daily basis. The patients were followed up on a daily basis in both the groups. Size of the ulcer was measured once in a 
week. Wound culture was obtained at the start of the treatment. Observed or spontaneously reported side effects (local and systemic) were documented. The patients were then subjected to split thickness skin grafting and the wounds were assessed on fifth post-operative day for skin graft up take. The total no of days of hospitalization were noted. The follow up of the patients were done at 7 days after discharge in outpatient department for post skin grafting complications. The results obtained were statistically evaluated and compared in each group.

The main parameters, which were analysed were No of days required for healing, Quality of graft bed and skin graft up take The variables were compared using the Unpaired Student"s

t-test. A $\mathrm{P}$ value $<0.05$ was considered significant.

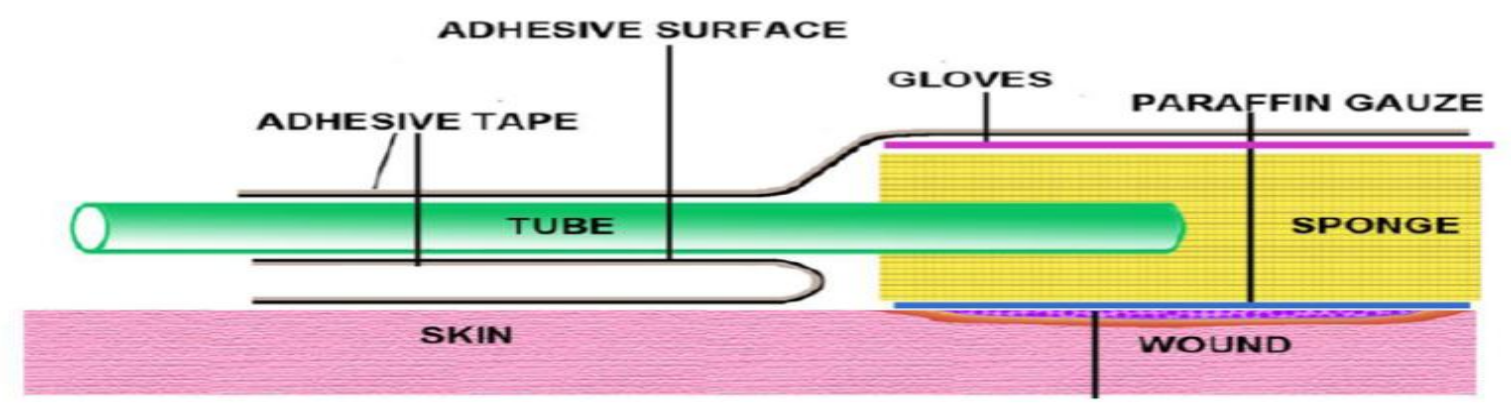

Schematic diagram of the NPWT method and air seal

\section{Results}

Table 1 shows the demographic data of 48 patients included in our study. The 48 patients admitted for the study were divided into two equal and comparable groups. Patients subjected to NEGATIVE PRESSURE WOUND THERAPY were classified as Study group and those who underwent conventional povidine iodine wound dressings were classified as control group.

The age of the patients varied from 35 to 75 years. Maximum number of cases belong to the age group of 35 to 45 years.

Among 48 participants, In both study and control group diabetes is more common among males compared to females. Among them $79.2 \%$ of the patients were male and $20.8 \%$ were female as shown in table 2 .

The patients in both groups were subjected to split thickness skin grafting as the final treatment modality. The graft up-take was then assessed at the end of the 5th post- operative day. In study group $93 \%$ graft take up was seen while it was $84 \%$ in the control group. Was show in table 3.

Table 4 Reveals comparison of parameters between conventional and npwt,

Duration of hospital stay as number of days of admission in the hospital.

The mean duration of hospital stay in Study group was 40.3 and 18.1 in the control group.

Table 1: Age distribution

\begin{tabular}{|l|c|c|c|}
\hline \multirow{2}{*}{ AgeGroup } & \multicolumn{2}{|c|}{ Type of Dressing } & \multirow{2}{*}{ Total } \\
\cline { 2 - 3 } & Conventional & NPWT & \multirow{2}{*}{$15(31.3 \%)$} \\
\hline $35-45$ & $7(29.2 \%)$ & $8(33.3 \%)$ & $13(27.1 \%)$ \\
\hline $46-55$ & $8(33.3 \%)$ & $5(20.8 \%)$ & $13(27.1 \%)$ \\
\hline $56-65$ & $6(25.0 \%)$ & $7(29.2 \%)$ & $7(14.6 \%)$ \\
\hline $66-75$ & $3(12.5 \%)$ & $4(16.7 \%)$ & $48(100.0 \%)$ \\
\hline Total & $24(100.0 \%)$ & $24(100.0 \%)$ & \\
\hline
\end{tabular}


Table 2: Sex distribution

\begin{tabular}{|l|c|c|c|}
\hline \multirow{2}{*}{ Sex } & \multicolumn{2}{|c|}{ Type of Dressing } & \multirow{2}{*}{ Total } \\
\cline { 2 - 3 } & Conventional & NPWT & \\
\hline Male & $21(87.5 \%)$ & $17(70.8 \%)$ & $38(79.2 \%)$ \\
\hline Female & $3(12.5 \%)$ & $7(29.2 \%)$ & $10(20.8 \%)$ \\
\hline Total & $24(100.0 \%)$ & $24(100.0 \%)$ & $48(100.0 \%)$ \\
\hline
\end{tabular}

Table 3: Graft Uptake (\%)

\begin{tabular}{|l|c|c|c|}
\hline \multirow{2}{*}{ Graft Uptake (\%) } & \multicolumn{2}{|c|}{ Type of Dressing } & \multirow{2}{*}{ Total } \\
\cline { 2 - 3 } & Conventional & NPWT & \\
\hline $71 \%-80 \%$ & $6(25.0 \%)$ & $2(8.3 \%)$ & $8(16.7 \%)$ \\
\hline $81 \%-90 \%$ & $14(58.3 \%)$ & $7(29.2 \%)$ & $21(43.8 \%)$ \\
\hline $91 \%-100 \%$ & $4(16.7 \%)$ & $15(62.5 \%)$ & $19(39.6 \%)$ \\
\hline Total & $24(100.0 \%)$ & $24(100.0 \%)$ & $48(100.0 \%)$ \\
\hline
\end{tabular}

Table 4: Comparison of parameters between Conventional and NPWT

\begin{tabular}{|c|c|c|c|c|c|c|c|}
\hline Parameters & Type of Dressing & $\mathbf{N}$ & Mean & $\begin{array}{c}\text { Std. } \\
\text { Deviation }\end{array}$ & $\begin{array}{c}\text { Mean } \\
\text { Difference }\end{array}$ & t-value & P-value \\
\hline \multirow{2}{*}{ Age (Yrs) } & Conventional & 24 & 53.38 & 10.749 & \multirow{2}{*}{-1.125} & \multirow{2}{*}{-0.371} & \multirow{2}{*}{0.713} \\
\hline & NPWT & 24 & 54.50 & 10.274 & & & \\
\hline \multirow[t]{2}{*}{ Graft Uptake \% } & Conventional & 24 & 84.13 & 6.402 & \multirow{2}{*}{-8.958} & \multirow{2}{*}{-4.722} & \multirow{2}{*}{$<0.01$} \\
\hline & NPWT & 24 & 93.08 & 6.737 & & & \\
\hline \multirow{2}{*}{$\begin{array}{l}\text { Duration of Hospital } \\
\text { Stay (days) }\end{array}$} & Conventional & 24 & 40.25 & 5.359 & \multirow{2}{*}{22.167} & \multirow{2}{*}{17.415} & \multirow{2}{*}{$<0.01$} \\
\hline & NPWT & 24 & 18.08 & 3.189 & & & \\
\hline \multirow{2}{*}{$\begin{array}{l}\text { Duration of Wound } \\
\text { (days) }\end{array}$} & Conventional & 24 & 14.71 & 1.654 & \multirow{2}{*}{0.000} & \multirow{2}{*}{0.000} & \multirow{2}{*}{1.000} \\
\hline & NPWT & 24 & 14.71 & 1.805 & & & \\
\hline \multirow[t]{2}{*}{ Duration of DM (Yrs) } & Conventional & 24 & 8.58 & 4.791 & \multirow{2}{*}{-2.792} & \multirow{2}{*}{-1.814} & \multirow{2}{*}{0.076} \\
\hline & NPWT & 24 & 11.38 & 5.822 & & & \\
\hline
\end{tabular}

\section{Discussion}

A prospective study of comparing NPWT with conventional wound dressing was done for patients presenting with diabetic foot ulcer. The study was done on 48 patients over a period of 2 years starting from 2017.

According to MilindRuke et al, mechanism of action of NPWT is it causes strain and stimulates cellular proliferation. It also causes mechanical evacuation of interstitial fluid. This in turn leads to increased micro circulation ${ }^{[6]}$ and there by secondary necrosis is reduced. NPWT is believed to accelerate wound healing by improving tissue oxygenation $^{[7]}$. In our study a standard pressure of $70-125 \mathrm{mmHg}$ of suction pressure was applied for all patients.NikunjVaidhya et al, studies showed that applying 70 -125 mmHg amount of pressure to a wound bed had the greatest effect on tissue re-growth and granulation tissue ${ }^{[8]}$. As the concept of outcome based medicine evolved, the need for better wound dressing modality became more acute.

Now wound dressing systems were compared not only on the basis of the rate of granulation tissue formed or the rate of wound healing but also on the cost and duration of hospital stay of the patient which was considered as a measure of morbidity of the patient. Study conducted by LokaVijayan Siddha et al on 100 study subjects, used NPWT over the study group \&amp; CWD over control group, showed mean age in study group was 56.4 yrs and 58.7 yrs in control group. In our study, mean age in study group was 54.50 yrs and 53.38 yrs in control group.

According to LokaVijayan Siddha et al, Graft take-up was $82.4 \%$ and $78.43 \%$ in Study \&amp; Control grouprespectively. In our Study graft uptake was $93.08 \%$ \&amp; $84.13 \%$ in study and 
control group respectively. LokaVijayan Siddha et al study showed hospital stay of 21 days in study group and 45 days in control group. In our study, hospital stay was days in study group 18.1days and 40.3 days in control group ${ }^{[9]}$.

A prospective study conducted by Kamran H etal from 2011 to 2013, 38 patients managed with vacuum assisted closure. Mean age was $56 \pm 7.8$ years. Twenty three patients presented with necrotizing fasciitis and 15 patients with gangrene. Lower limbs were involved in majority of the patients. Debridement or amputations were done. Vacuum dressing was changed twice weekly in outpatient department. Wounds were closed secondarily if possible or covered with split thickness skin graft in another admission. They found all the wounds were successfully granulated at the end of vacuum therapy. Mean hospital stay was 7.5 days. Vacuum dressing was applied for a mean of 20 days. There was reduction in the size of the wound. Thirteen patients underwent secondary closure of the wound under local anesthesia, 18 patients required coverage with split thickness skin graft and 7 patients healed with secondary intention. In our study, hospital stay was days in study group 18.1days and 40.3 days in control group ${ }^{[10]}$.

A prospective study done by Prabhdeep S etal, on 30 patients, which weredivided into two groups. One group received negative pressure dressing whileother group received conventional saline moistened gauze dressing. Resultswere compared for rate of wound healing. Results were, a statisticallysignificant difference in the rate of appearance of granulation tissue between the two groups; with granulation tissue appearing earlier in the study group. The study group promised a better outcome (80\% complete responders) ascompared to the control group (60\% complete responders $)^{[11]}$

A prospective study done by Sreelesh $\mathrm{S}$ etal An Easy Technique for Negative-Pressure Wound Therapy for Extremities Using Collagen Powder and SterileGloves from January 2015 to january 2016 they used this method for themanagement of extremity raw area in 20 patients. The indication was traumain 12 patients and diabetic foot wound in 8 cases. The age group ranged from 21 to 68 years. It was used for lower extremity wound in 16 cases and the restfor hand raw areas. The wound size ranged between 20 and $168 \mathrm{~cm} 2$. Themean wound size was $54 \mathrm{~cm} 2$. The median duration of NPWT application was9 days. The mean total and partial dressing changes were 2.8 times. Thenumber of NPWT applications ranged from 1 to 5 . In one case, the therapywas discontinued due to patient reasons. In all other cases, wounds becameclean, size was decreased, and good granulation growth could beachieved. ${ }^{[12]}$ In our study, All cases we achived good granulation tissue.

\section{Conclusion}

In the present study it was concluded that negative pressure wound therapy byforming healthy granulation tissue helps in better graft take up than the conventional dressing. Because of enhanced healing and overall hospital stay, the post operative complications were less in negative pressure wound therapy. Negative pressure wound therapy dressing can be considered as superior option in management of diabetic ulcers. An easy and cheap alternative method of NPWT to the extremity wounds using sterile surgical gloves. NPWT turned out to be a good alternative with respect to the duration and cost of treatment and ergonomically better in the management of extremity wounds. NPWP dressing thus is an effective, and widely available therapeutic agent in wound healing.

\section{Acknowledgment: Nil \\ Financial support: Nil}

\section{References}

1. Cohen I, Diegelmann R, Yager D, et al. Wound care and wound healing. 7th ed ed. New York: McGraw-Hill, 1999.

2. Influence of Risk Factors and Diabetic Complications on Peripheral Nerve 
Function in Type 2 Diabetes Mellitus. Rodica B, Bajko Z, Maier S, Voidăzan S, Moțăţăianu A. 1, 2015, Acta Medica Marisiensis, Vol. 61, pp. 40-46.

3. Lazarus GS, Cooper DM, Knighton DR, et al. Definitions and guidelines for assessment of wounds and evaluation of healing. Wound Repair Regen 1994; 2(3):165-70.

4. Shweiki E, Gallagher KE. Negative pressure wound therapy in acute, contaminated wounds: documenting its safety and efficacy to support current global practice. Int Wound J 2013; 10(1): 13-43.

5. Glass GE, Nanchahal J. The methodology of negative pressure wound therapy: separating fact from fiction. $\mathrm{J}$ Plast Reconstr AesthetSurg 2012; 65(8):9891001.

6. Microvascular complications of type 2 diabetes (UKPDS 35): Prospective observational study. BMJ 2000, 321:405412.

7. Milind R, Satish P, AmolP.Negative Pressure Wound Therapy for poorpatients in India-an observational case series. The Journal of Diabetic FootComplications, 2013;5(3):73-7.

8. Eberlein $\mathrm{T}$, Fendler $\mathrm{H}$. Using a new technique of negative pressure wound therapy (NPWT), variable pressure therapy (VPT), for the management of chronic, non- healing wounds. Clinical Symposium for Advanced Wound Care (SAWC; Dallas, Texas) 2009; April.

9. NikunjVaidhya ,ArpitPanchal. A New Cost-effective Method of NPWT in Diabetic Foot Wound Indian J Surg (December 2015) 77(Suppl 2):S525-S529.
10. Siddha LV, Shetty SK, Varghese T. Efficacy of Modified Vacuum Assisted Closure in Wound Healing. Int J Sci Stud, 2015;2(11):52-9.

11. Kamran H, Haroon R, Ghulam MK, Darshan K, Sunil K. Vacuum assisted closure- utilization as home based therapy in the management of complex diabetic extremity wounds. Pak J med sci.2015; 31(1):95-9.

12. Prabhdeep SN, Sanjeev KU, Ramneesh G, Kuljyot B, Shirin G. Role ofnegative pressure wound therapy in healing of diabetic foot ulcers. J SurgTech Case Report 2011;3:17-22.

13. Sreelesh LS, Laxminarayan B. An Easy Technique for Negative-PressureWound Therapy for Extremities Using Collagen Powder and Sterile Gloves.Indian J Surg 2017;79(1):81-3. 